\title{
TOXICITY OF SECONDARY COMPOUNDS TO THE SEED-EATING LARVAE OF THE BRUCHID BEETLE CALLOSOBRUCHUS MACULATUS
}

\author{
Daniel H. Janzen, ${ }^{*}+$ Harvey B. Juster* and E. Arthur Bell $\ddagger$ \\ *Division of Biological Sciences, University of Michigan, Ann Arbor, MI 48109, U.S.A.; $\ddagger$ Department of Plant Sciences, \\ University of London, King's College, 68 Half Moon Lane, London SE24 9JF U.K.
}

(Received 22 August 1976)

Key Word Index-Secondary compounds; toxicity in cowpea seeds: Bruchid weevil; alkaloids; amino acids.

\begin{abstract}
By incorporating various secondary compounds in the normal diet of larval Callosobruchus maculatus bruchids, we show that the effects of any particular compound are dosage-dependent. Alkaloids are generally the most toxic of the compounds tested. Non-protein amino acids are more toxic than protein amino acids but the latter can be toxic at 1 and $5 \%$ incorporation in the diet. The non-protein amino acid homoarginine has a salutary effect on larval survival at low concentrations. A variety of other secondary compounds found in seeds are toxic at various levels representative of those levels found in seeds in nature, and for all secondary compounds tested a $0.1-5 \%$ incorporation in the diet often has a detrimental effect on production of adult beetles. We conclude that many of the secondary compounds found in seeds are likely to be toxic to at least some animal, and thus are likely to be responsible at least in part for the extreme host-specifity shown by seed-eating insects.
\end{abstract}

\section{INTRODUCTION}

A primary adaptive role of secondary plant compounds is the repulsion of herbivores, either through direct toxicity or some indirect mechanism like distastefulness. Secondary compounds found in seeds seem to be no exception to this generalization, but with few exceptions [1-6] little detailed study has been made of their effects on seed-eating animals. Here, we report the results of incorporating small doses of secondary compounds found in seeds (and of a few secondary compounds found elsewhere) in the normal diet of the seed-eating beetle

† Present address: Department of Biology, University of Pennsylvania, Philadelphia, PA 19174, USA.

Table 1. Tests of significance comparing beetle production by control tablets and experimental tablets with amounts of alkaloids ( $t$ test; $*=<0.05, * *=p<0.01, * * *=$ totally lethal)

\begin{tabular}{|c|c|c|c|}
\hline Alkaloids (Source) $\ddagger$ & $0.1 \%$ & $\begin{array}{l}\text { Dose } \\
1.0 \%\end{array}$ & $5.0 \%$ \\
\hline $\begin{array}{l}\text { Caffeine (Aldrich) } \\
\text { Colchicine (Aldrich) } \\
\text { Erythrina flabelliformis seed } \\
\text { alkaloids (R.T.H.) } \\
\text { Gramine (E.L.) } \\
\text { Theobromine (Sigma) } \\
\text { Strychnine (Sigma) } \\
\text { Reserpine (Sigma) } \\
\text { Atropine (Sigma) } \\
\text { Nicotine sulfate (Sigma) } \\
\text { L-Ephedrine (Sigma) } \\
\text { L-Sparteine sulfate (Sigma) }\end{array}$ & $\begin{array}{l}* * \\
* * * * \\
* * * * \\
* * * * \\
* \\
* * * \\
* * * * \\
* * * * \\
* * *^{*} \\
* * * * \\
* * * *\end{array}$ & $* * * \dagger$ & \\
\hline
\end{tabular}

* Same results with $1.0 \%$ and $5.0 \%$

† Same results with $5.0 \%$.

$\ddagger$ Key to sources:- Aldrich: Aldrich Chem. Co., Milwaukee, Wisconsin, A. P.: A \& P Food Stores, Ann Arbor, Michigan, C. A. R.: C. A. Ryan, Dept. Agricultural Chemistry, Washington State University, Pullman, WA 99163. D. G. S.: D. G. Scarpelli, Univ. Kansas Medical Center, Kansas City, KA 66103; from Sterculia foetida oil. D. H. G. C.: D. H. G. Crout, Dept. Chemistry, Univ. Exeter, Exeter EX4 4QD, England. D. S.: D. Seigler and D. Kennard, Dept. Botany, Univ. Illinois at Champaign-Urbana, Urbana, IL 61801. E. A. B.: E. A. Bell, author. E. L.: E. Leete, Dept. Chemistry, Univ. Minnesota, Minneapolis, MN 55455. G. A. R.: G. A. Rosenthal, School of Biological Sciences, Univ. Kentucky, Lexington, KY 40506. I. E. L.: I. E. Liener, Dept. Biochemistry, Univ. Minnesota, St. Paul, MN 55101. K. D. S.: K. D. Sears, ITT Rayonier Inc., 409 East Harvard Ave., Shelton, WA 98584. M. F. B.: M. F. Betouski, Dept. Botany, Univ. Texas at Austin, Austin, TX 78712. R. G. C.: Dept. Biology, Univ. New Mexico, Albuquerque, NM 87131. R. T. H.: R. T. Hargreaves and K. L. Rinehart, Dept. Chemistry. Univ. Illinois at Champaign-Urbana, Urbana, IL 61801. Sigma: Sigma Chem. Co., St. Louis, MO.

Table 2. Tests of significance comparing beetle production by control tablets and experimental tablets with various amounts of non-protein amino acids and related compounds ( $t$ test; $*=p<0.05, * *=p<0.01, * * *=$ totally lethal)

\begin{tabular}{lccc}
\hline \multicolumn{1}{c}{$\begin{array}{c}\text { Non-protein amino acid } \\
\text { (Source) }\end{array}$} & $0.1 \%$ & $\begin{array}{c}\text { Dose } \\
1.0 \%\end{array}$ & $5.0 \%$ \\
\hline L-Homoarginine $(2 \times)$ (E.A.B.) & NS & NS & $* *$ \\
D,L-Pipecolic acid (2 $)$ (Sigma) & NS & NS & $* *$ \\
Albizzine (E.A.B.) & NS & NS & $* * *$ \\
S-Carboxyethylcysteine (E.A.B.) & NS & NS & $* * *$ \\
L-3,4-Dihydroxyphenylalanine & & & \\
$\quad(2 \times)$ (Sigma) & NS & NS & $* * *$ \\
$\gamma$-Glutamyl-L-tyrosine (E.A.B.) & NS & NS & \\
L-Djenkolic acid (Sigma) & NS & NS &
\end{tabular}


L-Canavanine $(2 \times)$ E.A.B.,

$$
\text { G.A.R.) }
$$

D,L-2,4-Diaminobutyric acid

(Sigma)

Isowillardiine (D.H.G.C.)

$\gamma$-Methylglutamic acid (E.A.B.)

Tyramine (E.A.B.)

$N$-Methyltyrosine (E.A.B.)

5-Hydroxy-L-tryptophan (Sigma)

$m$-Carboxyphenylalanine (E.A.B.)

$2(S), 3(S), 4(R) \beta$-Hydroxy- $\gamma$ -

methylglutamic acid (E.A.B.)

$\gamma$-Guanidinobutyric acid (E.A.B.)

$\gamma$-Aminopropionitrile fumarate

(Sigma)

L-Mimosine (Sigma)

B-Cyano-L-alanine (Sigma)

Azetidine-2-carboxylic acid

(E.A.B.)

5-Methoxy- $N, N$ -

dimethyltryptamine (Sigma)

3-Nitropropionic acid (Sigma)

L-3-carboxy-6,7-dihydroxy-1,2,3,4-

tetrahydroisoquinoline (E.A.B.)

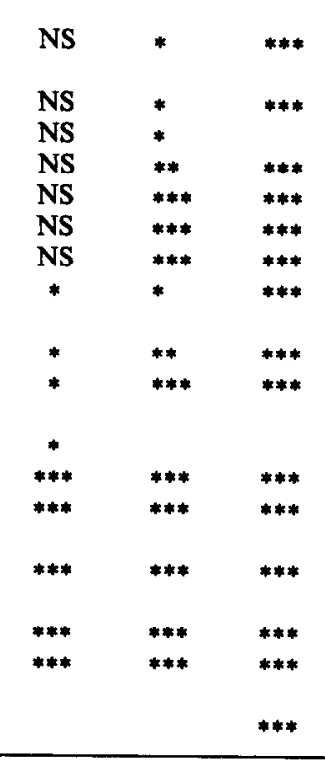

Callosobruchus maculatus (Bruchidae). The concentrations of the secondary compounds tested were generally representative of those found in seeds in nature.

C. maculatus is generally known as the southern cowpea weevil, and its larvae are major economic pests by eating cowpeas (Vigna unguiculata $=V$. sinensis) in the field and in storage. By adding secondary compounds from other plants to the diet of $C$. maculatus larvae, we are asking, in effect, what the impact would be on these larvae of a mutant cowpea seed that contained, say, $0.1 \%$ caffeine or $1 \%$ canavanine. In asking this question, we are indirectly seeing if the large array of secondary compounds found in seeds is of adaptive significance in preventing a very large portion (but not all) of the potential seed-predators in the habitat from feeding on this or that species of food.

\section{RESULTS}

\section{Alkaloids}

From the data in Table 1, it is obvious that southern cowpea weevils are broadly and highly susceptible to even very low concentrations of alkaloids. Of 11 tested, 9 were lethal at $0.1 \%$ concentration and the other two (caffeine and theobromine) had an effect; they were lethal at $1 \%$ concentration.

\section{Amino acids}

From the data in Table 2, it is evident that the different non-protein amino acids found in seeds are differentially toxic to cowpea weevil larvae, and that there are dosage effects. As an example of the actual data obtained, a detailed breakdown of the beetle emergence is shown (Table 3) from tablets with various concentrations of L-3,4-dihydroxyphenylalanine (L-DOPA), L-canavanine and $L$-homoarginine. In the case of L-DOPA, concentrations of $1-5 \%$ were tested; at 1 and $2 \%$, the controls and experimentals were significantly different at the 0.05 or 0.01 level, depending on the individual trial, but

Table 3. Detailed emergence records for L-canavanine, L-dopa, L-homoarginine, and black bean lectin trials

\begin{tabular}{|c|c|c|c|c|c|c|c|c|c|c|c|c|c|c|c|}
\hline \multirow[b]{2}{*}{ Tablet number: } & \multirow[b]{2}{*}{1} & \multirow[b]{2}{*}{2} & \multirow[b]{2}{*}{3} & \multirow[b]{2}{*}{4} & \multirow[b]{2}{*}{5} & \multicolumn{8}{|c|}{ Number of emerging adult beetles } & \multirow[b]{2}{*}{14} & \multirow[b]{2}{*}{15} \\
\hline & & & & & & 6 & 7 & 8 & 9 & 10 & 11 & 12 & 13 & & \\
\hline Control & 6 & 6 & 10 & 7 & 8 & 7 & 6 & 7 & 6 & 7 & 8 & 10 & 8 & 8 & $\begin{aligned} 9 \bar{x} & =7.53 \\
\text { S.D. } & =1.36\end{aligned}$ \\
\hline $0.1 \%$ L-DOPA & 6 & 7 & 8 & 8 & 8 & 6 & 5 & 9 & 6 & 7 & 6 & 7 & 5 & 9 & $\begin{array}{r}6 \bar{x}=6.87 \\
\text { S.D. }=1.30\end{array}$ \\
\hline $1 \% \mathrm{~L}-\mathrm{DOPA}$ & 7 & 4 & 7 & 5 & 10 & 6 & 5 & 7 & 7 & 7 & 4 & 5 & 7 & 8 & $\begin{array}{r}5 \bar{x}=6.27 \\
\text { S.D. }=1.62\end{array}$ \\
\hline $5 \%$ L-DOPA & 0 & 0 & 0 & 0 & 0 & 0 & 0 & 0 & 0 & 0 & 0 & 0 & 0 & 0 & $0 \bar{x}=0^{* * *}$ \\
\hline Control & 6 & 5 & 6 & 2 & 3 & 7 & 2 & 7 & 7 & 7 & 3 & 6 & 4 & 6 & $\begin{array}{r}8 \bar{x}=5.27 \\
\text { S.D. }=1.98\end{array}$ \\
\hline $0.1 \%$ Canavanine & 6 & 6 & 6 & 8 & 6 & 8 & 7 & 9 & 7 & 5 & 5 & 3 & 3 & 6 & $\begin{array}{r}8 \bar{x}=6.20 \\
\text { S.D. }=1.74\end{array}$ \\
\hline $1 \%$ Canavanine & 1 & 1 & 2 & 4 & 2 & 0 & 3 & 2 & 3 & 0 & 2 & 2 & 1 & 1 & $\begin{aligned} 3 \bar{x} & =1.80^{*} \\
\text { S.D. } & =1.15\end{aligned}$ \\
\hline $5 \%$ Canavanine & 0 & 0 & 0 & 0 & 0 & 0 & 0 & 0 & 0 & 0 & $\mathbf{0}$ & 0 & 0 & 0 & $0 \bar{x}=0^{* * *}$ \\
\hline Control & 2 & 4 & 4 & 1 & 2 & 5 & 2 & 4 & 3 & 2 & 4 & 4 & 2 & 2 & $\begin{array}{r}5 \bar{x}=3.07 \\
\text { S.D. }=1.28\end{array}$ \\
\hline $0.1 \%$ L-Homoarginine & 5 & 4 & 5 & 5 & 6 & 4 & 5 & 6 & 4 & 2 & 4 & 5 & 3 & 3 & $\begin{array}{r}5 \bar{x}=4.40 \\
\text { S.D. }=1.12\end{array}$ \\
\hline $1 \%$ L-Homoarginine & 3 & 5 & 4 & 4 & 1 & 3 & 2 & 5 & 4 & 2 & 6 & 7 & 6 & 4 & $\begin{array}{r}6 \bar{x}=4.13 \\
\text { S.D. }=1.73\end{array}$ \\
\hline $5 \%$ L-Homoarginine & 0 & 0 & 0 & 0 & 0 & 0 & 0 & 0 & 0 & 0 & 0 & 0 & 0 & 0 & $0 \bar{x}=0^{* * *}$ \\
\hline Control & 5 & 7 & 8 & 3 & 4 & 3 & 6 & 3 & 4 & 3 & 6 & 4 & 2 & 5 & $\begin{aligned} \bar{x} & =4.50 \\
\text { S.D. } & =1.74\end{aligned}$ \\
\hline $0.1 \%$ black bean lectin & 3 & 3 & 4 & 5 & 3 & 2 & 4 & 3 & 5 & 5 & 4 & 3 & 3 & 3 & $\begin{aligned} \bar{x} & =3.57 \\
\text { S.D. } & =0.94\end{aligned}$ \\
\hline $1 \%$ black bean lectin & 0 & 0 & 0 & 0 & 1 & 1 & 0 & 0 & 0 & 0 & 0 & 0 & 0 & 0 & $\begin{aligned} \bar{x} & =0.14^{* *} \\
\text { S.D. } & =0.36\end{aligned}$ \\
\hline $5 \%$ black bean lectin & 0 & 0 & 0 & 0 & 0 & 0 & 0 & 0 & 0 & 0 & 0 & 0 & 0 & 0 & $\bar{x}=0^{* * *}$ \\
\hline
\end{tabular}


Table 4. Effect of protein amino acids (Sigma) on on survival to adult life form of Callosobruchus maculatus in tablets made of cowpea flour

\begin{tabular}{lll}
\hline \multicolumn{1}{c}{ Protein amino acid } & \multicolumn{2}{c}{ Dose } \\
& $1 \%$ & $5 \%$ \\
\hline L-Arginine & NS & NS \\
L-Histidine & NS & NS \\
L-Proline & NS & NS \\
L-Alanine & NS & NS \\
L-Cysteine & NS & $* *$ \\
L-Lysine & NS & $*$ \\
L-Glutamic acid & NS & $* * *$ \\
L-Isoleucine & NS & $* *$ \\
L-Serine & NS & NS \\
L-Glycine & NS & $*$ \\
L-Tyrosine & NS & $* * *$ \\
L-Phenylalanine & NS & $* * *$ \\
L-Asparagine & $*$ & $*$ \\
L-Aspartic acid & $*$ & $* *$ \\
L-Cystine & $*$ & $* * *$ \\
L-Methionine & $*$ & $* * *$ \\
L-Tryptophan & $*$ & $* * *$ \\
L-Hydroxyproline & $* *$ & $* * *$ \\
L-Threonine & $* *$ & $* *$ \\
L-Valine & $* *$ & $* *$ \\
\hline & & \\
\hline & &
\end{tabular}

at 3,4 and 5\%,L-DOPA was always lethal and therefore the absolute tolerance level for L-DOPA by the southern cowpea weevil probably lies somewhere between 2 and $3 \%$ in the diet. However, for L-homoarginine the same experiment showed no effect on cowpea weevils for $1-3 \%$ inclusion in the diet, a highly significant reduction at $4 \%$ and highly significant to lethal effects at $5 \%$, depending on the trial.

The question now arises whether the effects of the non-protein amino acids are just those of adding an amino acid, or if there is something special about nonprotein amino acids. The data in Table 4 demonstrate that in fact protein amino acids added to the diet can also be detrimental to the bruchid larvae, but not nearly as much as are non-protein amino acids. For example, at $1 \%$ concentration, no protein amino acid was lethal, though $36 \%$ of them had a depressant effect on production of adult beetles; at the same concentration, $41 \%$ of the non-protein amino acids were lethal and another $27 \%$ had a depressant effect on production of adult beetles. At $5 \%$ concentration, still only $32 \%$ of the protein amino acids were lethal, while $90 \%$ of the nonprotein amino acids were lethal and all the rest had a depressant effect on production of adult beetles.

It is commonplace for 2 or 3 non-protein amino acids to be found in the same seed. In preliminary trials to work now in progress, we added $0.1 \%$ of each of two or three non-protein amino acids that had no effect by themselves at $0.1 \%$ concentration. The three mixtures L-canavanine plus $S$-carboxyethylcysteine, L-homoarginine plus Lcanavanine plus $N$-methyltyrosine, and $L$-canavanine plus $S$-carboxyethylcysteine plus L-homoarginine had no depressant effect on production of adult beetles. However, the combination of L-homoarginine plus L-canavanine had a highly significant elevating effect on production of adult heetles. it should be noted that in all other trials as well, addition of $0.1 \%$ homoarginine produced values well over the controls, though not statistically significantly so.

Combinations of non-protein amino acids that alone had no effect at $1 \%$ gave significant effects. Djenkolic acid plus D,L-pipecolic acid, and D,L-pipecolic acid plus albizzine at $1 \%$ concentration each had highly significant depressant effects on beetle production. Albizzine plus the lignan nordihydroquaiaretic acid (no effect at $1 \%$

Table 5. Tests of significance comparing beetle production by control tablets and experimental tablets with various amounts of miscellaneous compounds ( $t$ text; $*=p<0.05, * *=p<0.01$, $* * *$ = totally lethal)

\begin{tabular}{|c|c|c|c|}
\hline Miscellaneous compounds & $0.1 \%$ & $1 \%$ & $5 \%$ \\
\hline Glass beads (Sigma) & & & NS \\
\hline Ground cellulose (Sigma) & & & NS \\
\hline $\begin{array}{l}\text { Egg white trypsin inhibitor } \\
\text { (Sigma) }\end{array}$ & NS & NS & NS \\
\hline $\begin{array}{l}\text { Soybean trypsin inhibitor } \\
\text { (Sigma) }\end{array}$ & NS & NS & * \\
\hline $\begin{array}{l}\text { Potato proteinase inhibitor } \\
\text { (C.A.R.) }\end{array}$ & NS & NS & $* * *$ \\
\hline Black bean lectin† (I.E.L.) & NS & $* *$ & $* * *$ \\
\hline $\begin{array}{l}\text { Heat-inactivated black bean } \\
\text { lectint (I.E.L.) }\end{array}$ & NS & NS & NS $\ddagger$ \\
\hline Gibberellic acid (Sigma) & NS & NS & ** \\
\hline $\begin{array}{l}\beta \text {-Asarone (Sigma) } \\
\text { Glaucolide-A (M.F.B.) }\end{array}$ & $\stackrel{* *}{\text { NS }}$ & $* * *$ & $* * *$ \\
\hline $\begin{array}{l}\text { Cyclopropane fatty acid from } \\
\text { Sterculia foetida oil (D.G.S.) }\end{array}$ & $* * *$ & $* * *$ & $* * * *$ \\
\hline Coumarin (Sigma) & $* * *$ & $* * *$ & $* * *$ \\
\hline p-Hydroxybenzoic acid (Sigma) & NS & NS & $*$ \\
\hline Ferulic acid (Sigma) & $*$ & $* *$ & $* * *$ \\
\hline $\begin{array}{l}\text { p-Coumaric acid (Sigma) } \\
\text { Vanillic acid (Sigma) }\end{array}$ & $\begin{array}{l}\text { NS } \\
\text { NS }\end{array}$ & $\begin{array}{l}\text { NS } \\
\text { NS }\end{array}$ & $* * *$ \\
\hline Dicumarol (Sigma) & $* *$ & $* * *$ & $* * *$ \\
\hline $\begin{array}{l}\text { 3-( } \gamma \text {-acetonylbenzl)-4-hydroxy- } \\
\text { coumarin (Sigma) }\end{array}$ & $*$ & $* * *$ & **** \\
\hline $\begin{array}{l}\text { Condensed western hemlock } \\
\text { tannin (K.D.S.) }\end{array}$ & NS & NS & ** \\
\hline $\begin{array}{l}\text { Nordihydroguaiaretic acid } \\
\text { (R.G.C.) }\end{array}$ & NS & NS & $* * *$ \\
\hline $\begin{array}{l}\text { Cyanolipid-rich Koelreuteria } \\
\text { seed oil (D.S.) } \mid \Uparrow\end{array}$ & NS\$ & $* * * *$ & $* * *$ \\
\hline $\begin{array}{l}\text { Cyanolipid-rich Sapindus seed } \\
\text { oil (D.S.) } \mid \text { f }\end{array}$ & enhanced & $* * *$ & $* * *$ \\
\hline $\begin{array}{l}\text { Cyanolipid-rich Ungnadia } \\
\text { seed oil (D.S.) }\end{array}$ & **** & * & $* * *$ \\
\hline Ginger (A.P.) & NS & & NS \\
\hline Paprika (A.P.) & NS & & NS \\
\hline Nutmeg (A.P.) & NS & * & $* * *$ \\
\hline Allspice (A.P.) & NS & & $* *$ \\
\hline Cinnamon (A.P.) & NS & & ** \\
\hline Turmeric (A.P.) & NS & & **** \\
\hline Chili Powder (A.P.) & ** & & ** \\
\hline Cloves (A.P.) & $* *$ & & **** \\
\hline Mustard (A.P.) & $* *$ & & $* * *$ \\
\hline
\end{tabular}

$\dagger$ See [3] for more detailed discussion of these results. $\ddagger$ Also no significant effects when incorporated at $10 \%$ of the diet. || The concentration refers to the cyanolipid content in the tablet; the seed oil itself contains $34 \%$ to $67 \%$ cyanolipids depending on the species (D. Kennard and D. Weigler, personal communication). To get the cyanolipid into the medium, it was dissolved in ethanol, mixed with cowpea flour, dried, reground, and then pressed into a tablet; the controls were treated likewise except, no seed oil added. \& While there was no significant depressant effect of Koelreuteria seed oil at $0.1 \%$ cyanolipid concentration, the beotle production was highty significantly raised by this dose. 
concentration, Table 5) also significantly reduced beetle emergence.

\section{Other compounds}

A variety of other compounds were tried on the bruchids (Table 5); the highly toxic effect of black bean lectin has already been reported [3]. These compounds were chosen largely by availability and they simply give some idea of the variety of responses possible. However, with the exception of glass beads, ground cellulose, egg white trypsin inhibitor and inactivated black bean lectin, all had a negative effect on adult beetle production at concentrations of $5 \%$.

\section{DISCUSSION}

The extreme toxicity of alkaloids at $0.1 \%$ concentration in the diet is in agreement both with their pharmacological effect on animals in general and with their generally low concentration in seeds as compared to other secondary compounds. For example, most of the values of alkaloid content in a large survey of New Guinea plants were below $1 \%[7]$, and alkaloid content of seeds is generally well below $2 \%$. These values contrast strongly with the high concentrations of tannins of $5 \%$ or greater to be found in many plants and the values of 3-10\% non-protein amino acids found in many species of seeds e.g. $[4,5,8,9]$. In short, it appears that natural selection does not have to drive alkaloid concentrations in seeds to a very high level to result in the seed being largely toxic or inedible to an animal that does not normally prey on that seed. Of course, there are specialists on alkaloidcontaining seeds; sparteine occurs in high concentrations in the seeds of the legume Sarothamnus scoparius, and these seeds are fed on by host-specific weevils and bruchids [10]. The old world tropical bruchid genus Specularius is a seed predator of Erythrina seeds [11] However, it is of interest that it is much easier to find examples of insects that feed on seeds rich in uncommon amino acids than on seeds rich in alkaloids.

The great diversity of toxicity exhibited by the nonprotein amino acids leads to several conclusions. First, one cannot generalize without a priori knowledge as to what concentration of a particular compound will be toxic, except that if it is $5 \%$ or greater, the probability is very high that it will be lethal.

Second, there is no reason to expect other seed predators to display exactly the same pattern of susceptibility as shown by the southern cowpea weevil. However, it would not be surprising to find, for example, that azetidine-2-carboxylic acid is nearly always lethal at $0.1 \%$ while L-DOPA and L-homoarginine are only rarely so. We base this hypothesis on the observation that certain non-protein amino acids are probably of a structure such that, if one living non-specialist cell can deal with them, most living non-specialist cells can deal with them. In short, if the same set of non-protein amino acids were tested against an array of bruchid species, it is likely that certain compounds would always require high doses for lethality, others would always be toxic at low doses, and others would vary strongly from species to species. However, we still do not know what the chemical traits of these three groups of non-protein amino acids are, and whether their abundance in nature agree with their lethality. If L-DOPA always requires high concentrations, does it occur in seeds in high concentrations or not at all; if L-mimosine is always lethal at low concentrations, does it occur in seeds in concentrations that vary greatly among species of plants?

Third, compound-specific dosage rate are expected from a class of compounds like non-protein amino acids. Their toxicity will generally be manifest through their particular ability to compete with other protein amino acids in protein synthesis or in other biosynthetic pathways involving protein amino acids, and possibly through the amount that can be tolerated when incorporated into protein before malfunction becomes lethal to the animal. In this context, non-protein amino acids may be viewed as intermediate between compounds like alkaloids and cyanide that simply block a particular internal physiological reaction, and compounds like tannins that bind with a substrate or enzyme in the gut and prevent its use by the animal.

A protein amino acid may also prove to be toxic in a feeding trial. First, if the normal diet of the animal is exceptionally poor or lacking in a particular protein amino acid, addition of that protein amino acid may be just as traumatic as the addition of a non-protein amino acid. It is of interest in this context that three of the eight protein amino acids that depressed beetle production at $1 \%$ incorporation in the diet were tryptophan, cystine and methionine which all occur in exceptionally low concentrations in cowpeas [12-14]. Second, animals are sufficiently finely tuned to their diets so that the ratios of protein amino acids in the diet influence the rates of protein amino acid uptake and use. An excess of L-hydroxyproline, if not normal for the diet of southern cowpea weevils, may disrupt the supply-demand balance in protein synthesis as surely as a low dose of $m$-carboxyphenylalanine. On the other hand, since most animals already have the physiological machinery for dealing with protein amino acids, it seems unlikely that natural selection would often result in an elevation of the concentration of one of them as a defense against seed predators; effective counterattack through coevolution by the seed predator, taking the form of increasing the rate of use or avoidance of the excess protein amino acid, seems a fairly likely outcome and might even occur through physiological acclimatization if time is available.

A general discussion of the impact of other secondary compounds on southern cowpea larvae will have to wait until more information is available. However, a few patterns are clear. Inert materials like fine glass beads and cellulose have no effect on the beetle larvae at concentrations as high as $5 \%$, and thus the effects of the other compounds used in our study cannot be viewed as merely the outcome of nutritional dilution. Trypsin inhibitors had little or no effect, as expected since cowpeas like other legume seeds contain trypsin inhibitors and thus the southern cowpea weevil must be physiologically prepared to deal with them [1]. Southern cowpea weevils could not deal with high concentrations of proteinase inhibitors from potatoes, however, suggesting that their defense against proteinase inhibitors is not total. Lectins from black beans (Phaseolus vulgaris) had a severe effect at concentrations approximating those found in commercial black beans, emphasizing that lectins can determine host specificity of bruchids just as can other secondary compounds [3]. The remaining ten pure compounds tested (see Table 5) all show strong negative effects at $5 \%$ concentrations, but variable effects at lower amounts. The three sapindaceous seed oils were all 
very toxic at 1 and $5 \%$ concentration in the diet, a concentration well below that found in the seeds in nature. However, the Koelreuteria seed oil at a $0.1 \%$ concentration nearly doubled the number of bruchids produced. This emphasizes the capricious possibilities of any new mutant with new higher concentrations of secondary compounds in the seeds. The spices, since they are complex mixtures of secondary compounds and nutrients cannot be analyzed in any detailed way. Suffice to note that their toxicity increases with concentration and at $5 \%$, only ginger and paprika had no effect on southern cowpea weevils.

We conclude that some secondary compounds found naturally in seeds are toxic to at least one species of seedeating insect and probably to many more. We also suspect that these secondary compounds are in great part responsible for the host-specificity displayed by the insects that eat seeds containing high concentrations of secondary compounds. The response of one species of animal to a large array of compounds is sufficiently varied that it will probably be always impossible to predict with absolute certainty the effect of a compound to which it is naive, at least at concentrations of $5 \%$ or less in the diet. Nevertheless, it is likely that non-protein amino acids added to the usual diet will always be more toxic than protein amino acids added in the same amounts, and alkaloids will be more toxic than non-protein amino acids.

\section{EXPERIMENTAI}

Commercially-purchased dried cowpeas were ground to a fine flour in a Wiley mill and stored in large plastic bags until needed. For control seeds, the flour was pressed into cylindrical tablets ('seeds') of $17 \mathrm{~mm}$ dia $\times 7 \mathrm{~mm}$ depth. These tablets were of uniform hardness and too hard to crush between the fingers, but not as hard as the original seeds. In making the experimental tablets, the secondary compound was added to the flour and thoroughly mixed in before pressing the mix into a tablet. The tablet press was hand constructed. Control and experimental tablets were stored in constant humidity chambers before oviposition and during incubation. Some unidentified process in the laboratory sometimes resulted in one set of controls being quite different from another (compare controls for L-DOPA with other controls in Table 3); for this reason it was necessary to compare experiments only with controls treated in exactly the same manner except for the addition of secondary compounds.

When female cowpea weevils in culture bottles were presented with the tablets, they oviposited freely on the surfaces of all tablets except those containing aromatic spices. The tablets were placed in the culture bottles for a few min, removed, and all eggs but ten scraped off the surface of each pill. This number of eggs results in little, if any, competition between the bruchid larvae for food. Emergence from 5-30 control tablets was compared with that from 5 or more experimental tablets. The tablets were then allowed to incubate for approximately two months, and the numbers of emerging beetles recorded. On average, 3.5 to 6 beetles emerged from control tablets. It is possible that some beetles which emerged as adults were crippled sexually or otherwise, but for the present study, only the effect of the secondary compound on the number of emerging adult beetles was considered. The humidity in the incubation chamber was maintained at approximately $80 \%$; drier conditions occasionally result in premature beetle death while higher humidities result in fungal attack of the tablets. Such humidity control is generally not required with seeds infested by cowpea weevils, but the seeds, in contrast to the tablets, do not dry severely at laboratory humidities.

Our stocks of cowpea weevils were derived from laboratory stocks at the USDA Insect Research and Development Laboratory, Savannah, Georgia (Dr. E. Jay). They had gone through at least $\mathbf{3 0}$ generations in the senior author's laboratory but since they are stored product pests, we have no reason to believe that they differ in any important way from freshly harvested samples.

Cowpeas are exceptionally free from high concentrations of secondary compounds. They contain no alkaloids or nonprotein amino acids, or other notable secondary compounds with the exception of protease inhibitors [12, and laboratory of E. A. Bell]. It is certain that with the exception of the protein amino acids, cellulose, and trypsin inhibitors, the southern cowpea weevil is physiologically naive to all the compounds tested in this study.

Acknowledgements-This study was supported by NSF grants GB-35032X and BMS75-14268, and SRC grant B/RG/56163. We greatly appreciate the contribution of chemicals by the persons identified in Table 1. The manuscript was constructively reviewed by H. G. Baker, R. Cates, C. M. Pond and M. M. Martin.

\section{REFERENCES}

1. Applebaum, S. W. (1954) J. Insect Physiol.10, 783.

2. Janzen, D. H. (1975) Evolutionary Strategies of Parasitic Insects and Mites (Price, P. W., ed.), pp. 154-186. Plenum Press, New York.

3. Janzen, D. H., Juster, H. B. and Liener, I. E. (1976) Science 192, 795.

4. Rehr, S. S., Bell, E. A., Janzen, D. H. and Feeny, P. P. (1973) Biochem. Syst. 1, 63.

5. Rehr, S. S., Janzen, D. H. and Feeny, P. P. (1973) Science 181, 81.

6. Rosenthal, G. A., Dahlman, D. L. and Janzen, D. H. (1976) Science 192, 256.

7. Levin, D. A. (1976) Am. Nat. 110, 261.

8. Bell, E. A. and Janzen, D. H. (1971) Nature 229, 136

9. Bell, E. A., Fellows, L. E. and Qureshi, M. Y. (1976) Phytochemistry 15, 823 .

10. Parnell, J. R. (1966) J. Anim. Ecol. 35, 157.

11. Bridwell, J. C. (1968) J. Wash. Acad. Sci. $28,69$.

12. Johnson, R. M. and Raymond, W. D. (1964) Trop. Sci. 6, 68.

13. Evans, R. J. and Bandemer, S. L. (1967) J. Agric. Fd Chem. $15,439$.

14. Sevilla-Eusebio, J., Mamaril, J. C., Eusebio, J. A. and Gonzales, R. R. (1968) Philipp. Agric. 52, 211. 